\title{
Instructors' Perspectives of Their Initial Transition from Face-to-face to Online Teaching
}

\author{
Sharon Phillip, Margaret Cain \\ School of Education \\ The University of the West Indies \\ St. Augustine, Trinidad and Tobago
}

\begin{abstract}
This study examined instructors' perspectives about their first-time experience in as they transitioned from the face-to-face to online mode of delivery of a B.Ed. Primary (Language Arts) program. It was the first and only fully online program at the School of Education, The University of the West Indies (UWI) St. Augustine Campus, Trinidad. The study used a qualitative methodology to gain an understanding of the instructors' experiences in teaching in a fully online environment. Six instructors in the program were selected using a purposive sampling strategy. The participants had a range of experience in the use of digital and online technology. Data were collected through semi-structured interviews. The findings revealed that some of the instructors experienced challenges in negotiating the online milieu. Others never made a transition to online delivery but simply transferred their face-to-face strategies and techniques to the online classes. In some cases, instructors had to confront their core beliefs about teaching and learning as they navigated the dynamics of the online environment. Additionally, instructors had to question their identity as teachers. Overall, the instructors faced issues related to their pedagogy, their classroom practices, and the power relations in the virtual classroom, which challenged their identities as teachers.
\end{abstract}

\section{Introduction}

In 2007-2008 the School of Education at The University of the West Indies (UWI), St Augustine launched a new initiative, an online Bachelor of Education Primary (Language Arts) program. The Bachelor of Education Primary (Language Arts) had been taught in the traditional face-to-face mode for several years. However, in partnership with The University of the West Indies, Open Campus (UWIOC), a fully online version of the program was created in an effort to cater to the changing needs of inservice teachers at the primary level. It was the first time that a fully online program was offered at the School of Education. Both the face-to-face and online versions of the program were run concurrently and were taught by the same instructors.

The program was delivered using a Moodle based platform, the Learning Exchange. The main mode of delivery was online tutoring with two or three audio conferences to support teaching and learning. However, in the first year of the online version the foundation courses for the program were face-to-face classes.

In preparation for online delivery, all instructors attended a workshop that exposed them to the Learning Exchange. Most of the instructors were familiar with another Moodle based interface but it was not used as extensively for teaching as they were expected to do for the online program. They were trained in the use of online tools and activities for student participation in the courses. Some of the tools they explored were discussion forums, quizzes and using wikis. During of the program, instructors received technical support to deal with any issues they faced with the online environment as well as the use of the online tools.

Additionally, since this was the first offering of the fully online version, instructors had to create the course content for the individual courses. The face-to-face version of most of the courses did not have set texts so instructors relied on information from a variety of sources and provided students with a reading list to supplement the lectures and class discussions. However, for the online version of the courses instructors created course manuals with the key information, student activities and reading lists, inclusive of links to online articles, in an effort to provide detailed guidance for students in manageable chunks.

Despite the initial training and available technical support, instructors had a variety of challenges. Among the issues they faced were the navigation of the online platform, student engagement and the general management of the online teaching and learning. This prompted the researchers to begin a comprehensive exploration of the instructors' experiences and beliefs about teaching and learning in the online environment.

This study reports on the experiences of six instructors who were involved from the initial offering 
of the online version of the Bachelor of Education Primary (Language Arts) program. Instructors in this study refer to both e-Tutors and Course Coordinators who managed the individual courses within the program. The findings are limited to a specific sample and context so they cannot be generalized. However, the research was expected to provide insights into the instructors' experiences. In addition, it would highlight areas that needed to be improved to enhance the delivery of the program.

The research questions the study sought to explore were:

1. What are instructors' views of online teaching?

2. How, if at all, does the instructor's identity change as the teaching environment changes?

\section{Literature Review}

A major development in higher education institutions across the world has been the movement to online education. Online programs offer opportunities to students who may otherwise have little or no access to tertiary level education. With the proliferation of online programs, many instructors are expected to move from the traditional approaches of face-to-face teaching to teaching in the online environment. [4] Suggest that to successfully transition from traditional pedagogy to active online learning pedagogies, instructors may need to alter the teaching styles used in their face-to-face classrooms and embrace new skills to effectively reach the online learner. However, [4], [11] emphasized the need for research that focuses on instructors in such situations and on the challenges they face in the transition from face-to-face to online delivery. As the numbers of online offerings increase, there is a growing body of research that focuses on different aspects and dimensions of instructors' experiences.

Gonzalez [8] for example, focused on the conceptions of, and approaches to, teaching online of seven lecturers who had a recent experience teaching post-graduate online units at an Australian university. The study, which used a phenomenographic approach, gathered data using in-depth interviews with each of the seven lecturers. Three conceptions of online teaching emerged in the study: the web for individual access to learning materials and information, and for individual assessment; the web for learning related communication (asynchronous and/or synchronous; and the web as a medium for networked learning. Two broad approaches to online teaching emerged: focus on informative/individual learning; and focus on communicative/networked learning. Contextual factors - institutional influence, nature of the students and of the subject - were found to have different levels of influence on the approaches to online teaching.

Attention was also given to pedagogical change in the research literature [10]. Examined the impact that the introduction of new instructional web-based technologies is likely to have on established pedagogical practices. Viewed from a sociological perspective, he argued that the pedagogical ecology (the teaching and learning environment) of the asynchronous online course can redefine the traditional roles of instructors and learners, focus greater attention on how students will learn instead of simply what one will teach, and provide a context for interactive forms of learning. [6] expressed a similar view, saying that the focus should be on understanding the learner and that practice of online teaching should engender mutuality, respect, and trust and foster a transformative learning environment. Jaffee further noted that an important indication of the power of pedagogical ecology is seen when instructors report changes in their philosophy and approach to teaching as a result of their experience in delivering a Web-based course.

Other fundamental change issues become apparent with the introduction of online teaching. [16] suggests that for educators, it includes a number of issues including possible changes in their identities. Wallace examined the learning and development of a work group engaged in an online innovation and critiqued its processes and outcomes in light of, among other things, the construction of a work identity.

Teacher identity is an elusive and complex concept. However, there appears to be some agreement that it comprises the images, experiences and expectations that teachers have held and continue to hold about themselves and their pedagogy [1], [17]. The images are reflected in the metaphors teachers use to describe themselves and are useful in exploring teacher identity

[14], [17] Many authors suggest a variety of metaphors to characterize the role of online instructors. Instructors are viewed as facilitators of the process and content, coordinators, planners, change agents, moderators, weavers, assessors, advisors, communicators, researchers, guides, models, helpers and technologists [2], [9], [15].

Becoming an effective instructor in the online environment involves, among other things, the provision of meaningful and engaging learning experiences for students. Opportunities for learning should be guided by sound principles [3]. Proposed seven principles of good practice that can be applied to both online and face-to-face environments. These principles are: student-faculty contact, student-student collaboration, active learning, prompt feedback, focus on time on task, communication of high expectations, and respect for diverse abilities. Studies such as the one by [18] have used these principles to gain a better understanding of online teaching. Zhang and Walls 
explored online instructors' perceptions of their implementation of Chickering and Gamson's seven principles and the factors that influenced the instructors' implementation of same. The findings revealed that adherence to the seven principles by instructors varied significantly from one principle to another. Instructional strategies and technology features were found to have a positive influence on the implementation of the seven principles, while time and distance negatively influenced the implementation.

\section{Methodology}

A qualitative approach was used in this study to gain an understanding of how instructors transition from teaching in a face-to-face mode to teaching in a fully online program. In order to obtain an in-depth understanding of the phenomenon, six instructors in the B.Ed. Online Primary (Language Arts) program were selected for the study using a purposive sampling strategy. Purposive sampling facilitates the selection of cases, which allow the researcher to discover, understand, and gain insights into the phenomenon under study [13], [19].

To maintain anonymity and confidentiality, pseudonyms have been given to the participants. The participants (three males and three females) were selected from different kinds of courses and had a range of experience in the use of computer and online technology: Kent was an e-tutor in a Theatre course with a field-based practicum and was fairly competent with the computer and online technology; Richard was a coordinator of a school development course with a field-based practicum, but had limited competence with the computer; Mary was an e-tutor and eventually became a coordinator of an education foundation course and was fairly competent with the computer; Brandon was also the coordinator of an education foundation course, and was very competent with the computer; Susan was an e-tutor and eventually became the coordinator of a course on the use of media and production of educational materials, and was very competent in the computer and the use of online technology; Karen was an e-tutor in an English Language course and was fairly competent with the computer and online technology. The instructors were all resident in Trinidad, except for Karen who lived in Tobago.

Data were collected through audio-taped interviews with the participants. The interviews were semistructured and sought to determine: the instructors' views about online teaching, how they transitioned from teaching in the face-to-face mode to teaching in the online mode; and how, if at all, their identity had changed as they moved to teaching in the online environment. Verbatim transcription was done of all of the interviews. The data analysis process involved coding the data, comparing the codes, and grouping similar or related codes to form categories. It was a continuous, iterative process in which the codes and categories generated were constantly reviewed and refined.

Two key strategies - member checking and peer review - were employed in this study to establish trustworthiness or credibility of the findings. Member checking involved taking the data (the transcripts) back to the participants and asking them to clarify any areas of uncertainty in the data as well as any issues arising out of on-going analysis. In addition, the researchers sought to ensure that their interpretations of the data were in sync with the participants' meanings. In peer review, both researchers analyzed the transcripts; this involved preliminary analysis of the transcripts independently, and then meeting to compare and discuss the codes assigned to the data, and the emerging categories. Peer review provided a check on the data analysis process, and assisted in "exploring aspects of the inquiry that might otherwise remain only implicit within the researcher's mind" [12].

\section{Findings}

The analysis revealed that there was a range of experiences in the instructors' transition from face-toface to online teaching. The findings are organized according to five broad categories - instructors' philosophy of online teaching, pedagogical approaches, benefits of online teaching, challenges and instructor identity.

\subsection{Instructors' beliefs about online teaching}

Instructors articulated different philosophies of online teaching. One instructor viewed online teaching as a correspondence course supported by email interaction. Another felt that the face-to-face mode allowed for greater flexibility and creativity than the online mode. An instructor who taught a practical course expressed reservations about doing it online. Others had more progressive views that were in keeping with the expectations and demands of online teaching.

The instructors thought that online education provided greater accessibility for adults with many responsibilities to further their education. For example, Karen indicated:

The online environment really enables someone to continue with their job and their family life, while getting a degree. And structuring their time so that they can study at their own convenience, and also connect with other students in their classes.

Susan, who had previously been exposed to 
working in the online environment, found that face-toface teaching and online teaching were totally different. She felt that the preparation and design of online materials was crucial for effective delivery and that it allowed the instructor to concentrate on managing activities and interaction with students. Brandon believed that online teaching needed interactive materials and activities and these had to be reflected in the course materials.

Karen felt that online teaching encouraged more awareness of the importance of language of communication for human connection/humanizing the course. She noted:

I think what online teaching did for me is that in my writing, especially in my responses, I became a lot more aware of words I was selecting in responding, so as to ensure that students got from me, a sense of sincerity and that I am accessible. Because it wasn't going to be face-to-face and there is already that degree of distance, the language that we use when we respond to students, especially their questions and difficulties, had to be warm.

In addition she noted:

The program facilitated, as far as I am concerned, creating that unity and community that really eliminated any sense of distance.

There were mixed views about the capability of the online environment to facilitate meaningful interaction. Karen believed that the online environment encouraged students to develop a community of learning. However, both Richard and Brandon felt that online teaching encouraged students to hide in the background and avoid active participation in the classes/sessions. Brandon was convinced that online interaction is impersonal:

I think people who are typing and even saying things online, I think online people could be what they want to be and say what they want to say. I think there is not the same level of integrity. But when you have face-to-face interaction and people could read one another's body language, intensity of speech, facial expression and the passion that is sort of lost online.

He also felt that it doesn't foster the affective and social aspects of teacher preparation:

Once you're talking about fundamental training, fundamental things like getting to work with others in groups, to change their basic attitude and values, I feel online can't do it because an online person is not a real person.

Similarly, Richard expressed a strong belief in physical presence in the classroom.

\subsection{Pedagogical approach}

Overall the data revealed varied pedagogical approaches used in both face-to-face and online delivery. Before their courses started the instructors were exposed to an orientation to online teaching and learning as mentioned earlier. Yet, the instructors navigated the online Learning Management System (LMS) in different ways. Initially it was used as a repository for course materials by all of the instructors. As the instructors became more familiar with the available online tools they incorporated some of them in their classes in an effort to move from a more didactic delivery to a student-centered/interactive mode. However, generally they used only the discussion forum. Kent attempted to use blogs but had limited success because he was unable to sustain student interest. Richard, on the other hand, did not fully accept and acknowledge the capability of online tools to facilitate learning. Therefore, he tended to transfer his face-to-face instructional approach to the online class. He noted, "Online was a different form of the face-to-face instruction."

While the instructors all used the discussion forum in their classes, only one, Susan, explored additional online tools. She acknowledged: "Most people think PowerPoint is the be all and end all of using technology but there is so much more than that." She incorporated audio, video and graphics to cater for the different learning styles and the wide variety of individuals. In addition, she provided web links to free software such as Audacity and Photo Story and other materials, and organized activities that encouraged her students to develop technological skills and create tools to facilitate learning. She stated:

I like the idea of empowering the teacher to use the technology in their teaching but I've also realised that knowing about technology doesn't necessarily mean that you will use technology.

Also, Susan emphasised the need for her students to learn how to integrate technology in specific subject areas. Thus, she provided scaffolding in various forms including embedded links for free tutorials.

\subsection{Benefits of online teaching}

There were many benefits from the online course for both instructors and students. It encouraged reflection on the instructors' pedagogy. Brandon noted that having to adapt to online teaching and learning to create more interactive sessions influenced him to make changes to the face-to-face version of his courses. Kent felt that the training workshop helped him to develop proficiency with the technology as well as producing materials for online delivery. Susan was convinced that her skill with writing the online course materials improved over time since she was catering for a 'faceless' audience who did not always have access to synchronous delivery. Moreover, some instructors learnt to use technological tools to 
humanize their courses so that their students did not experience isolation. Karen, who used podcasts to help humanize her course, pointed out:

Voice gives it a human element so you're not just reading what is put there but there is a degree of connection that you get when you hear the voice of your lecturer. So even if you can't put a face to the person who is teaching you, you can get a voice.

The instructors felt that their students benefited in various ways. Student were empowered to take responsibility for their learning. They developed technological skills and learnt to create appropriate teaching materials for the students in their classrooms. They came to appreciate the international nature of the online program as they interacted with students from across the Caribbean. More importantly, the program facilitated flexible part time study at their own pace and allowed access to education for adults who were unable to attend face-to-face classes because of their responsibilities.

\subsection{Challenges}

Teaching in the online milieu presented a number of challenges for the instructors. Since this mode of teaching was new to most of them, they experienced some difficulty in understanding and navigating the LMS. On one end of the spectrum there was Kent who made minimum use of the LMS and resorted to using emails for communication with students. At the other end was Susan who explored many of the tools offered on the LMS and even incorporated tools and software from the Internet to facilitate her delivery and student learning. Others gradually adapted to the LMS but used either the discussion forum alone or included podcasts.

In addition to use of technological tools, some instructors experienced difficulty creating materials and interactive sessions despite the support given by Instructional Designers. Part of the problem was that they attempted to write the materials as if they were dealing with a face-to-face class.

The major problem was managing student participation and interaction in the courses. Most of the instructors indicated that some students rarely or never participated in the online discussions. They tended to visit the course page and read what was written by their peers without making an input in the discussion even when these discussions were graded. However, Mary attempted to minimize this by calling on individuals to respond to her questions. She advised:

...try as many strategies as possible so that your student will gravitate towards entering the discussion. Use whatever strategies like by name calling, asking questions, picking on them; do whatever you have to do so that you can have interaction at the end of the day.
Providing student feedback was another major challenge. In the online milieu feedback is critical for students. Generally the instructors found it difficult to manage it in a timely manner as well as to respond to individual students. Susan explained:

That was the biggest hurdle because you find yourself spending so much time responding to each individual student. Then you may decide the same thing to the entire group.

Her strategy for dealing with this was to strike a balance in providing one-on-one and whole group feedback:

It's a mixture of both. you have to use. Because if you are not responding to

each individual student, then the student may feel you're not reading my work; I'm out there all alone; in my little world and there is nobody communicating with me. So you have to balance responding to each student individually and broadcasting to the entire group when you find the question repeated by all the students or the majority of the students.

Kent had a unique challenge. His course had a heavy practical component. He had to find ways to create and manage student interaction and did not believe that online delivery would suffice. Initially, he reflected:

The course is the Theory and Practice of Educative Theatre and it didn't make sense to me how we could attend to the practice online. I had real, real questions about that. So I was the person who said from the word go that will not work.

Nevertheless, he attempted to use blogs and videos to support student learning. However, these strategies were eventually abandoned. He firmly believed that a blended approach would be more appropriate for this course.

So that's why I am pro the blended learning....you have the online component but you also have some kind of face-to-face happening inside of it.

\subsection{Instructor identity}

Generally, the data revealed that for most of the instructors in the study there was little or no change in their identity as they moved from the face-to-face to online environment. Some characterized themselves as traditional teachers. Richard showed the least change in his approach to teaching and continued to view himself as a disseminator of content knowledge. He admitted that he simply transferred himself into the online environment. Mary defined herself as a broadcaster, another traditional role. She explained:

$I$ used, the radio concept, the radio announcer concept...A radio announcer would be talking to people; the people are not in front of the radio 
announcer but you know people are listening to you. So if I have to say what it was like, it's that concept for me.

Further, she viewed herself as a moderator who constantly sought out her students to participate in discussions in the online forum. Brandon was also positioned himself as a traditional lecturer. He felt compelled to stick slavishly to the packaged course materials and believed that it was not possible to incorporate current events in his course. He noted:

In teaching in face-to-face, some topics would be what happened yesterday.... While in the online, I imagine you could force it in a discussion but it is a different thing.... There is a kind of a packaging in the online that I found a little bit suppressive of the flexibility and creativity that you would have in the face-to-face....There is a spontaneity, a flexibility, that face-to-face has, that the online didn't; that you couldn't implement easily.

Kent's situation was unique. Initially he saw himself as a facilitator of the workshop style delivery but changed to more of a traditional lecturer. He had to teach a usually highly interactive course in the online environment and struggled to capture the essence of the course. He resorted to a more passive lecture style online. He explained:

Teaching online turns the course into lectures as opposed to workshops, so it was really a question of switching gears and just doing a lecturer/facilitator type of thing. We provide the readings; we guide by asking hopefully the right questions; we set assignments that perhaps weren't even in the course, meaning that if we can find ways to issue challenges to participants, that may be a way to get them to experiment and/or to practice.

Two of the instructors were more innovative in their approach. Karen portrayed herself as a networker, excited by the opportunity to interact with persons from other parts of region:

It excited me to go online every year that I got a group; I liked to look to see where they were from. I was particularly interested in seeing people from St. Lucia, St. Vincent and Barbados. It further enhanced the idea of UWI as a regional institution. Because here I am in my little corner in Tobago, I've not met any of these people before, and I'm interacting with them and so on.

She also saw herself as a communicator who was entrusted with the responsibility of humanizing the course.

Because it wasn't going to be face-to-face and there is already that degree of distance, the language that we use when we respond to students, especially their questions and difficulties and things like that, the language had to be warm....They know it's not just a task master waiting for this to get done, but that there is still a human connection at the end of the "Enter here" or "Click here" .... and often I used a smiley face or raised eyebrows or something else so that it comes across as human.

Susan, like Kent, taught a practical course but was able to manipulate the online environment to retain the practical nature of the course and to achieve the desired learning outcomes. She defined herself in several ways. She played the role of facilitator, researcher and enabler. As an enabler, she empowered her students to create their own resources and develop strategies to use the available technology with their students. As facilitator, she provided online scaffolding, pointed them to key Internet links to enhance their learning experience and organized interactive sessions to encourage participation in the course. In her role as researcher, Susan kept abreast of emerging technologies and shared the knowledge with her students. She explained:

I do a lot of research. I do a lot of reading because IT is changing so much and there is so much new information out there, I go online and I search for information and search for different ways of doing different things. I read a lot of books, I read the journals.

Susan also noted that "the students are usually more on the cutting edge than the you are" hence the need to continually upgrade one's skills and competencies.

\section{Discussion}

The instructors in the study had different conceptions of online teaching. Their views were influenced by their extensive experience with face-toface teaching. As such, most of them adhered to tried and tested methods that they used in their classes. They did not feel that online teaching could allow for as much flexibility and creativity as face-to-face delivery. There was also the belief that online teaching does not foster the affective and social aspects of teaching, an important component in teacher education. Moreover, some had doubts about the ability to have meaningful interaction in the online environment. Yet, generally they agreed that online learning is valuable since it allows for greater accessibility for adult learners and empowers students to take responsibility for their learning. In addition, it facilitated networking among students from across the Caribbean. They also acknowledged the importance of creating interactive materials and activities and humanizing the course in order to enrich the learning experience for students.

With regard to navigating the online environment, the instructors had a variety of experiences. Initially, the Learning Management System (LMS) was used as a repository for course materials. Later, the instructors 
made greater use of online tools, although the discussion forum remained the only tool most used. Typically, they recognized the greater need for scaffolding since they were working in a virtual environment.

The instructors reported several benefits from online teaching. They developed some proficiency with the use of technology to deliver their courses and developed a greater skill in writing course materials for online delivery. For some, the experience of planning for and teaching online encouraged reflection on their face-to-face delivery. Often, they made improvements to their face-to-face classes based on their online experience.

Teaching in the online environment presented some challenges for the instructors. From a technical perspective, using the LMS was a new experience and some had difficulties navigating it and taking advantage of the range of available tools and capabilities. There were challenges to create online materials and interactive sessions to encourage student participation. In one case, there was no textbook for the face-to-face version of the course so the instructor had to create the online materials from scratch. Added to this, delivering a practical course in online environment was difficult. Most instructors felt that their students wanted instant feedback in the online environment and they weren't able to meet those expectations of the students. Further, managing student participation and interaction proved to be a challenge.

Generally, there was little or no change in the instructors' identity from the face-to-face to online environment. They tended to stick to the traditional role of lecturers with some variations. One instructor defined herself as a broadcaster and delivered the course to her audience. She also saw her role as a moderator of online discussions and encouraged her students to be active participants. Another instructor portrayed herself as a networker who managed interaction among students across the region. The role of communicator was also emphasised by this instructor, who placed importance on the use of language to humanize the course. One instructor highlighted her changed role from lecturer to facilitator, researcher and enabler. She created opportunities for student empowerment and continually explored new technologies and strategies to improve the students' learning experiences. Interestingly, one instructor switched from the role of facilitator to lecturer. He was challenged to adequately deliver a practical course that was previously taught using workshops in the face-toface mode, in the digital environment.

\section{Conclusion}

A number of recommendations for teaching and learning emerged from the findings of this study. The instructors experienced difficulties in using the Learning Management System and this highlighted the importance of having a user-friendly interface to minimize these issues. As a result of the challenges they faced with the online delivery and student engagement, it was felt that instructors should incorporate strategies to enhance their personal presence in their courses. Further, attention should be paid to the andrological principles in the design and development of online courses to facilitate successful delivery. The need to for a blended approach for practical courses with some opportunities for face-toface sessions emerged as a key factor for effective delivery.

The research also revealed that students experienced challenges with the technology. Thus, the importance of student engagement with technology prior to enrolment in online programs was underscored.

\section{References}

[1] Calderhead, J. (Ed.). (1987). Exploring teacher thinking. London: Cassell.

[2] Cantor, J. A. (2001). Delivering instruction to adult learners (Rev. ed.). Toronto, Ontario, Canada: Wall \& Emerson. (ERIC Document Reproduction Service No. ED469267).

[3] Chickering, A. W., \& Gamson, Z. F. (1987). Seven principles for good practice in undergraduate education. AAHE Bulletin, 39(7), 3-7.

[4] Cowan, P., Neil, P., \& Winter, E. (2011). Face-zine the future: Moving from face-to-face to online teaching. Project funded by the Higher Education Academy, Subject Centre for Education. ESCalate Themed funding: Teacher Educators for the 21st Century Grant Project Final Report. Retrieved from http://escalate.ac.uk/downloads/8458.pdf

[5] Creswell, J. W. (2012). Qualitative inquiry and research design: Choosing among five approaches $\left(3^{\text {rd }} \mathrm{ed}\right.$.). Thousand Oaks, CA: Sage.

[6] De Gagne, J. C., \& Walters, K. J. (2010). The lived experiences of online educators: Hermeneutic phenomenology. MERLOT Journal of Online Learning and Teaching, 6(2), 357-366. Retrieved from http://jolt.merlot.org/vol6no2/degagne_0610.htm

[7] Dickmeyer, N. (1989). Metaphor, model, and theory in education research. Teachers College Record, 91 (2), 151160.

[8] Gonzalez, C. (2009). Conceptions of, and approaches to, 
teaching online: A study of lecturers teaching postgraduate distance courses. High Educ, 57, 299-314. doi: 10.1007/s10734-008-9145-1.

[9] Goodyear, P., Salmon, G., \& Spector, J.M. (2001). Competences for online teaching: A special report. Educational Technology Research and Development, 49, 6572 .

[10] Jaffee, D. (2003). Virtual transformation: Web-based technology and technological change. Teaching Sociology, 31(2), 227-236. Retrieved from http://www.jstor.org/stable/3211312

[11] Keengwe, J., \& Kidd, T. (2010). Towards best practices in online learning and teaching in higher education. MERLOT Journal of Online Learning and Teaching, 6(2), 533-541.

[12] Lincoln, Y. S., \& Guba, E. G. (1985). Naturalistic inquiry. Newbury Park, CA: Sage.

[13] Merriam, S. B. (2009). Qualitative research: A guide to design and implementation. SanFrancisco, CA: Jossey-Bass.

[14] Munby, H. (1986). Metaphor in the thinking of teachers: An exploratory study. Journal of Curriculum Studies, 18 (2), 197-209.

[15] Rogers, J. (2000). Communities of practice: A framework for fostering coherence in virtual learning communities. Educational Technology and Society, 3, 384-392.

[16] Wallace, M. (2002). Managing and developing online education: Issues of change and identity. Journal of Workplace Learning, 14(5/6). 198-208. Retrieved from http://www.emeraldinsight.com/1366-5626.htm

[17] Weber, S. \& Mitchell, C. (1995). That's funny, you don't look like a teacher: Interrogating images and identity in popular culture. London: Falmer.

[18] Zhang, J., \& Walls, R. (2006). Instructors' selfperceived pedagogical principle implementation in the online environment. The Quarterly Review of Distance Education, 7(4), 413-426. 